\title{
EXPERIMENTAL STUDY OF ROCK RUPTURES' SHEAR STRENGTH ANISOTROPY
}

\author{
Tomáš PROISL * and Rostislav MELICHAR
}

Department of Geological Sciences, Faculty of Science, Masaryk University, Kotlářská 2, 61137 Brno, Czech Republic

*Corresponding author's e-mail: 327940@mail.muni.cz

\section{ARTICLE INFO}

Article history:

Received 27 September 2021

Accepted 20 January 2022

Available online 13 February 2022

Keywords:

Shear strength

Anisotropy

Joints

Faults

\section{ABSTRACT}

Joints significantly reduce rock cohesion compared to unfractured rock, but the question is what effect the possible anisotropy of the shear strength of different types of rupture has on possible subsequent failure. Both natural samples of granodiorite with natural joints and fault surfaces and gypsum models have been tested on the Matest A129 Rock shear box apparatus. The shear strength of preexisting ruptures was measured under a fixed normal stress component. The anisotropy of the shear strength of the joints and fault surfaces reached more than $60 \%$ of maximum strength, which is a very important value for solving structural loads. The shear strength was analyzed with polar plots. The pattern of the real joints typically showed a teardrop shape with one peak of strength in a certain direction and a minimum in the opposite direction. On the contrary, striated fault surfaces are characterized by two axial directions of minimal shear strength, i.e., longitudinal and transverse, and by two axial oblique directions with maximal shear strength, so the strength distribution in the polar graph has a four-cornered shape. The study showed that the anisotropy of the shear strength of various types of ruptures is their important feature.

\section{INTRODUCTION}

Fractures significantly reduce rock cohesion in comparison to unfractured rock. Depending on their size and penetrability, three basic types of fracture structures can be distinguished, such as faults, joints, and cleavage (Suppe, 1985; Van der Pluijm and Marshak, 2004). Joints and faults are the most common brittle structures that disrupt the continuity of rocks (Barton and Choubey, 1977; Kulatilake et al., 1995, 1999). Faults are discontinuous deformation structures with a macroscopically visible displacement of blocks usually larger than $1 \mathrm{~mm}$ due to the effect of shear stresses (Suppe, 1985). On the other hand, joints are discontinuous deformation structures with no macroscopically visible displacement of the blocks. Joints arise by tension or pressure (Van der Pluijm and Marshak, 2004; Suppe, 1985), or due to changes in the thickness of the planar body or the different material properties of the individual layers. Other types comprise anthropogenic joints or shock joints (Suppe, 1985; Van der Pluijm and Marshak, 2004). In natural outcrops, the separation of joint planes is usually greater than $1 \mathrm{~cm}$, while the separation of cleavage discontinuities is generally less than $1 \mathrm{~cm}$. Cleavage, a macroscopically almost penetrative structure, is a transition to metamorphic foliation. Its discontinuity can be observed in a microscopic study (Ragan, 2009).
The study, monitoring, and comparison of mechanical rock ruptures are some of the important issues in applied geological research. In order, e.g., to assess deep repositories (e.g., Bailly et al., 2014; Sosna et al., 2014), the structural stability of surface mines (e.g., Osasan and Afeni, 2010; Salvini et al., 2015), to assess subsidence related to the development of sinkholes (e.g., Navarro et al., 2014) and the extraction of fluids in geothermal fields (e.g., Glowacka et al., 2010; Sarychikhina et al., 2011), or to understand the initiation and behavior of rockslides and other slope failures (e.g., Nordvik et al., 2010; Agliardi et al., 2013; Cloutier et al., 2015).

The strength of preexisting ruptures is one of the basic parameters of characterizing tectonically disturbed rock as an input for numerical modeling (e.g., Baroň et al., 2005) and for construction purposes (Kulatilake et al., 1999). To determine the rupture strength, we must primarily know what affects the strength of the intact massive rocks. This depends mainly on the weathering of the ruptures and the texture and structure of the rock. The strength and deformation behavior of fractures also depends on their surface roughness (Maerz et al., 1990; Kulatilake et al., 1995; Kabeya and Legge, 1997; Xia et al., 2003; Yang et al., 2011), as fracture surfaces are not completely simply planar and smooth. The mechanical properties of fractures are, among others, influenced 

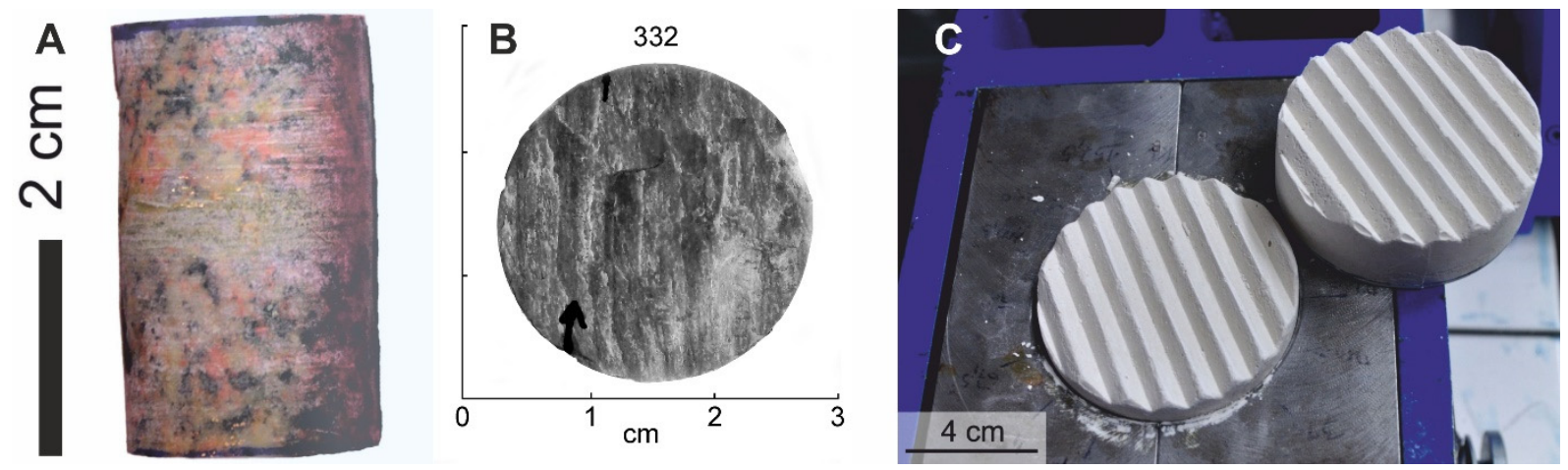

Fig. 1 Samples analyzed for shear strength anisotropy: A, B - real granodiorite samples with preexisting rupture, side view (A) and striated fault surface (B); C - gypsum model (type A) with the lower and upper parts.

by the shape, size, and number of individual contacts between the particular surfaces (Gentier et al., 1999; Grasselli and Egger, 2002, 2000; Cottrel et al., 2011). These properties can collectively be referred to as the above-mentioned roughness (Kabeya and Legge, 1997; Kulatilake et al., 1995; Van der Pluijm and Marshak, 2004).

Previous research has dealt primarily with the roughness and overall appearance of the rupture surface as a basic parameter for artificial models with relatively accurate castings of ruptures usually on gypsum (Yang et al., 2001) or a mixture of gypsum and sand (Kulatilake et al., 1995, 1999). Other variables in the experimental models, such as the effect of water, the rupture range, and the degree of weathering, were almost neglected (Kulatilake et al., 1995, 1998, 1999; Yang et al., 2001, 2011; Wang et al., 2019).

Most of the studies mentioned above considered the strength of natural fractures as a more or less directionally isotropic feature. However, in a closer view, it is evident that the joint and fault surfaces are anisotropic because of the fracture steps and plumose structures on the joint surfaces, striation, asymmetric microridges or trailed grains on fault surfaces, and such associated oblique fractures as tensile fractures, Riedel or P-shears, and other structures (see Petit, 1987; or Doblas et al., 1997, among a large number of others). These asymmetrical structures modify the surface morphology of fractures, which is reflected in joint strength, which should therefore be anisotropic as presented by Grasselli and Egger $(2000,2002)$ or Kulatilake et al. $(1995,1999)$. The main aim of the presented study was to quantify the shear strength anisotropy of real fractures with natural discontinuities. To better understand the behavior of predisposed fractures, the simplified and idealized rupture model using gypsum blocks was developed and used (here called the 'ideal rupture model').

\section{METHODS}

For the study of the strength of real joints, samples of 'Královo Pole' granodiorite (the Brno
Pluton, Bohemian Massif) with natural joints and fault surfaces were used. This granodiorite rock is a pinkish medium-grained rock (Fig. 1A), containing approximately $53 \%$ plagioclase, $25 \%$ quartz; $11 \%$ potassium feldspar, and $6 \%$ biotite, which is present in the form of euhedral columns up to $1 \mathrm{~cm}$ in size (Štelcl and Weiss, 1986). This Cadomian granodiorite was subjected to Variscan orogenesis, during which it was densely cracked under conditions that reached up to the facies of green schists, so metamorphic chlorite, epidote, and calcite can also be observed (Figs. 1A, B).

Granodiorite samples were taken by manual core drilling in the Vranov quarry (coordinates: N 49.297082, E 16.6034163), where well-exposed rocks with numerous fractures of different types can be found. Even though the granodiorite is densely jointed, it was very difficult to find samples with fractures that would not fault apart each other along the preexisting joint to be able to measure the original strength of the joint. In addition, it was necessary to obtain a sufficiently large piece of unsplit rock to be able to take several samples in the required orientation to measure the anisotropy of such a fracture. Despite these difficulties, three joints and two microfaults (Fig. 1B) were tested in eight different directions.

Each of the selected ruptures was sampled with oriented drill cores, so the samples were cylindrical with a diameter of $24 \mathrm{~mm}$ and a length of $30 \mathrm{~mm}$. To keep the original orientation, the samples were marked before drilling. On the fault surfaces, the zero direction was parallel to the striation in the direction of tectonic movement ( $\operatorname{slip}$ direction $=0^{\circ}$ ). As the direction of movement cannot be identified in the case of joints, the zero direction was defined randomly but uniformly for a given joint. Because the samples were destroyed by performing the tests, it was not possible to test the same sample multiple times. To achieve more statistically significant results, multiple samples of each particular rupture were taken in the eight defined directions (up to 16 samples per single rupture).

The samples were tested on the Matest A129 Rock shear box apparatus (MATEST, 2019). This portable shear box apparatus was invented primarily 
A
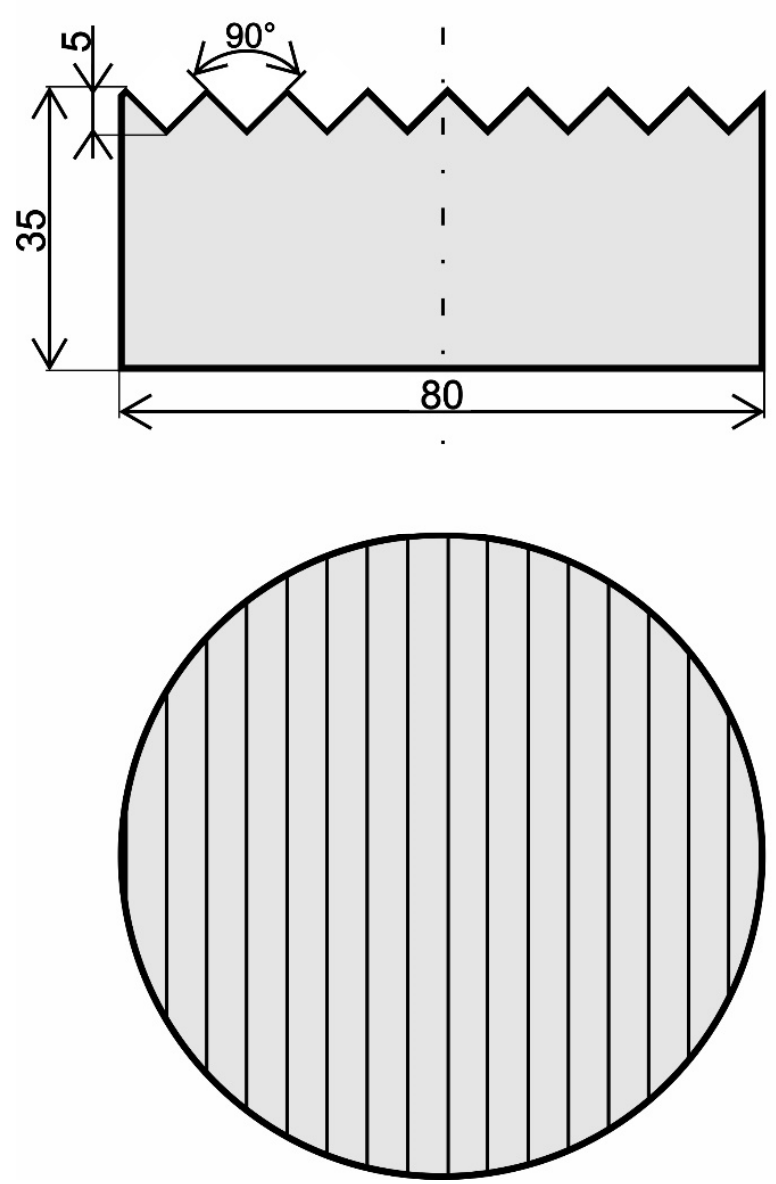

B
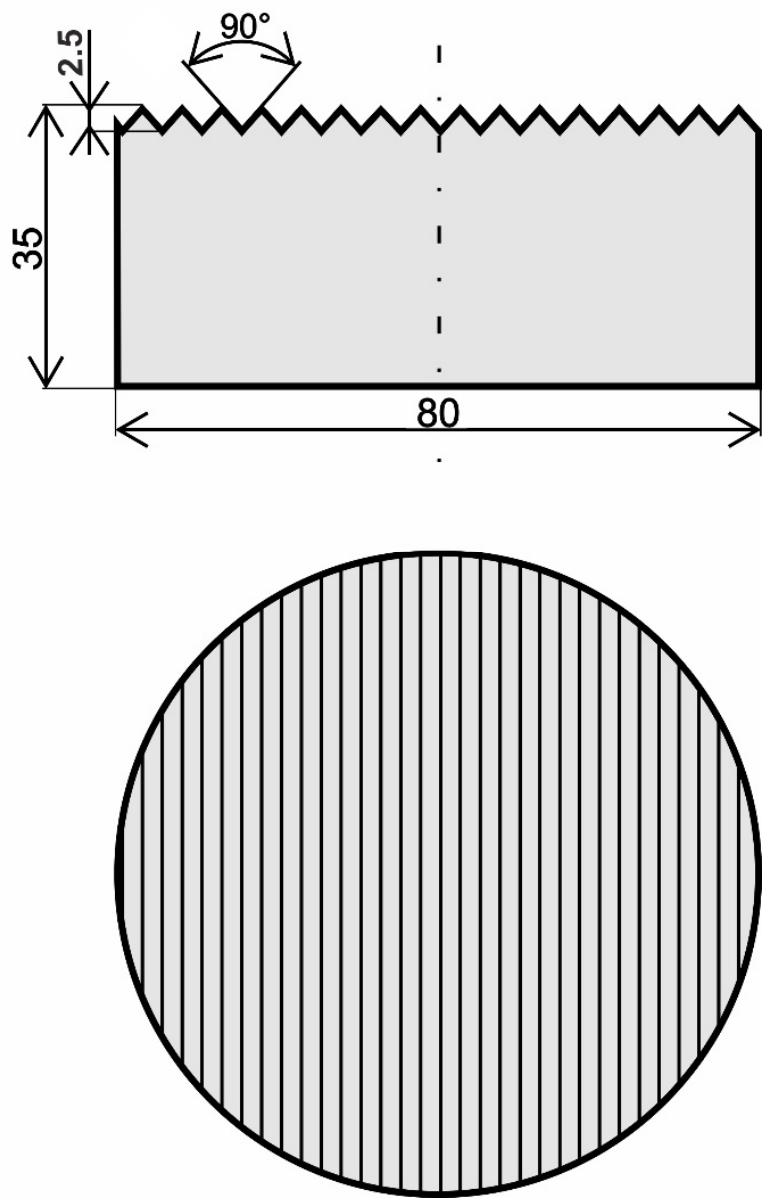

Fig. 2 Schematic geometry of the striated fault surface modeled by experimental gypsum samples (A, B - models types). Sizes in millimeters.

to test for discontinuities in rocks. It allows performing shear tests on cubic samples or drill cores, up to $12.5 \mathrm{~cm}$ in diameter. The applied force ranges from 0 to $50 \mathrm{kN}$ (Instruction Manual, 2006). The shear strength values were obtained under a fixed normal stress component equal to $22 \mathrm{MPa}$. The shear strength data were plotted on the polar diagrams already used by Kulatilake et al. (1995).

To analyze the anisotropy properties of the fracture strength, a simplified experimental gypsum model, in which the joints have defined roughness, was used (Fig. 2). A simple surface shape with parallel ridges and mirror symmetry was preferred. The shape of the ridges was an equilateral right triangle in crosssection. The model was prepared in two different types which differed only in the size of the ridges. The ridge height of $5 \mathrm{~mm}$ was chosen for type A, while for type $\mathrm{B}$ this height was only half of it, i.e. $2.5 \mathrm{~mm}$. Both models had a diameter of $80 \mathrm{~mm}$ and a height of each side of $35 \mathrm{~mm}$ (Figs. 1C, 2). Ten series of model type A (160 casts) and 11 series of model type B (176 casts) were processed.
Due to the transverse and longitudinal mirror symmetry of the model surfaces, it was not necessary to test all directions $\left(0-360^{\circ}\right)$ as with the real nonsymmetrical ruptures. Therefore, the gypsum models were tested only in 5 different directions in the range of $0^{\circ}$ to $90^{\circ}$, and the strength values achieved were used symmetrically for the other directions in the range of $90^{\circ}-360^{\circ}$. The direction parallel to the striations of the gypsum model surfaces was selected as the "zero" direction.

The gypsum models were tested on the same Matest A129 Rock shear box apparatus (MATEST, 2019), samples were loaded with a constant normal pressure of $11 \mathrm{MPa}(10 \mathrm{kN})$.

\section{RESULTS}

The results obtained from natural joints and faults, and gypsum models will be presented in the following. As will be shown, individual fractures showed different patterns of shear strength anisotropy, when the anisotropies of the joints formed one group 

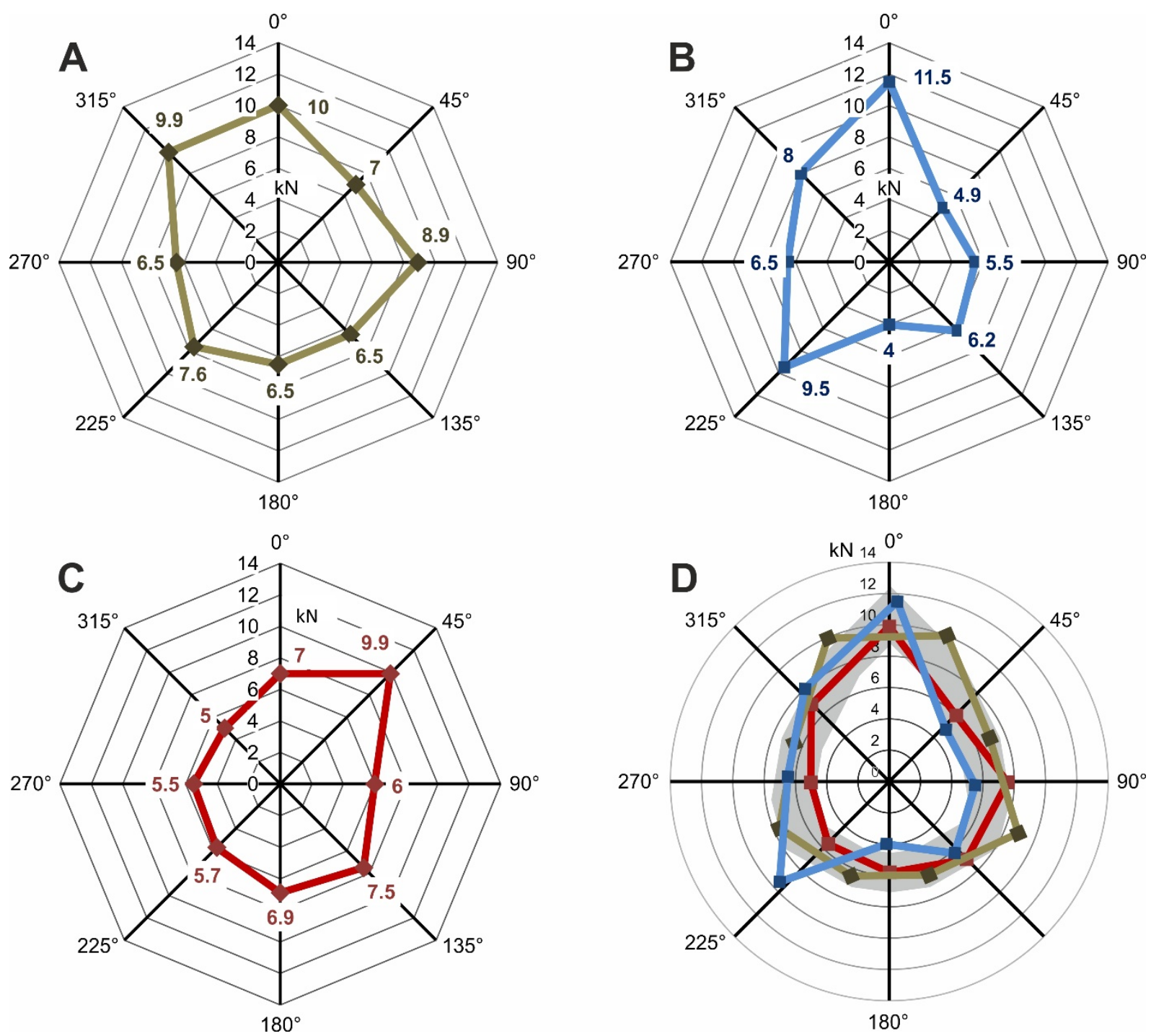

Fig. 3 Polar diagrams of the shear strengths of natural joints as a result of testing ('Královo Pole' granodiorite): $\mathrm{A}, \mathrm{B}, \mathrm{C}$ - various joints studied (original orientation); D - possible fit of teardrop-shaped strength patterns.

and the fault surfaces and gypsum models formed another group.

The three analyzed natural joints show approximately the same teardrop pattern of strength (Fig. 3) as the strength has one direction with the maximum value and the minimum strength is usually in the approximately opposite direction. The strength in other directions gradually decreases from maximum to minimum. The pattern thus has mirror symmetry in the transverse direction, whereas it is antisymmetric in the longitudinal direction.

The degree of strength anisotropy was different for each joint. The highest value of strength anisotropy was found in joint $\mathrm{B}$, where the shear strength ranged between 4.0 and $11.4 \mathrm{kN}$ (see Fig. 3B). The shape of the strength pattern is significantly notched in minimum, so the teardrop shape slightly turns heart-shaped.
In the case of the "A" joint, we observed the smallest difference $(3.5 \mathrm{kN})$ between the maximum shear strength $\left(0^{\circ}-10.0 \mathrm{kN}\right)$ and the minimum one $\left(270^{\circ}\right.$; respectively $180^{\circ}$ and $\left.135^{\circ}-6.5 \mathrm{kN}\right)$. In this case, we observed a significant secondary maximum of $8.9 \mathrm{kN}$ at $90^{\circ}$. The last, the joint ' $\mathrm{C}$ ', showed a clear maximum of $7.0-9.9 \mathrm{kN}$ at $0^{\circ}-45^{\circ}$, and a secondary maximum of $7.5 \mathrm{kN}$ at $135^{\circ}$. Other values ranged between 5.0 and $6.9 \mathrm{kN}$.

We tested two different types of natural faults: (i) with epidote filling (Fig. 4A) and (ii) with distinct striations (Fig. 4B). Both faults show a roughly square pattern of shear strength distribution, with the centers of the sides sometimes being slightly raised or slightly notched, i.e., in the longitudinal and transverse directions to the striae, the strengths are the smallest, while in the oblique directions, the strengths are large. 

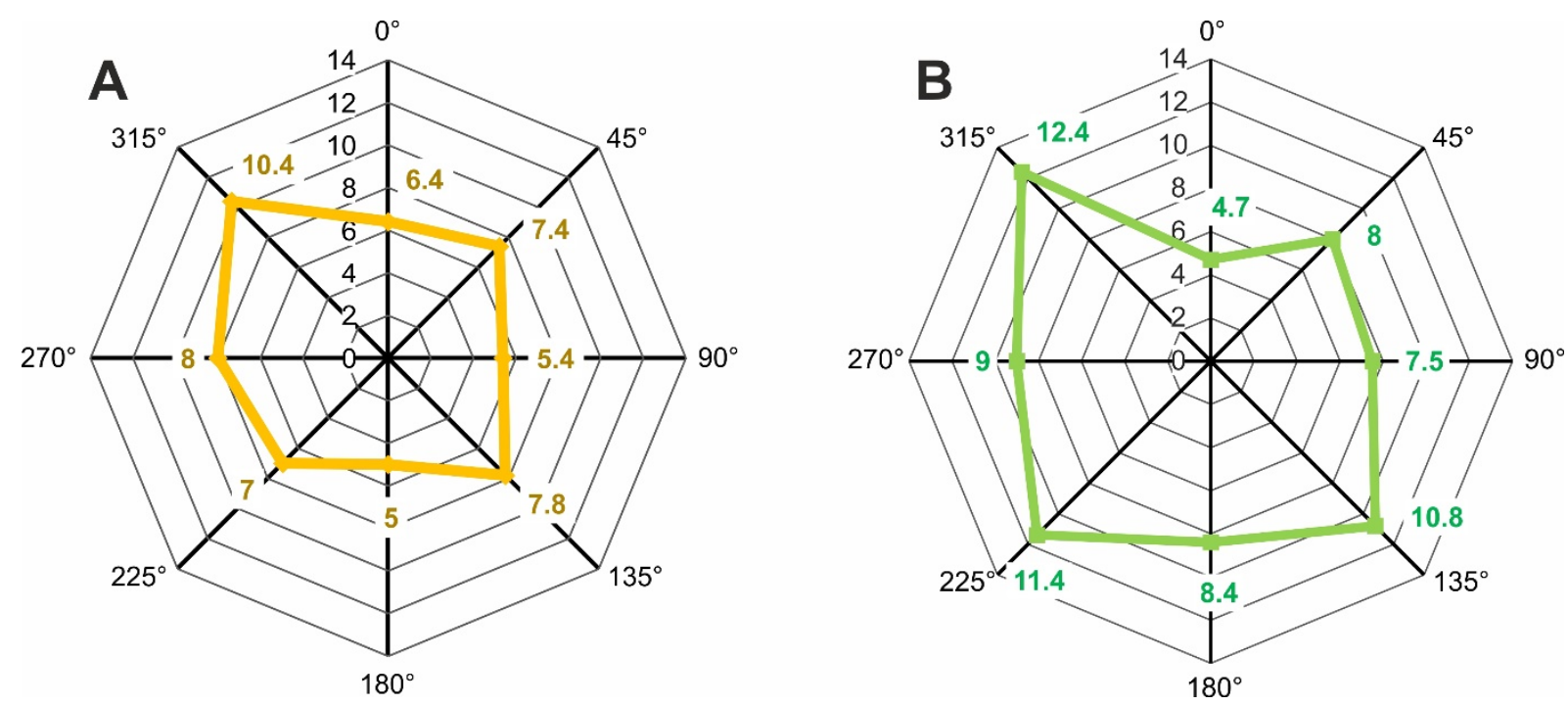

Fig. 4 Polar diagram of shear strength with the fault testing results: A - the microfault with the epidote filling; $\mathrm{B}$ - the microfault with the distinct asymmetrical striae.

The measured shear strength of all natural faults tested ranged between 4.7 and $12.4 \mathrm{kN}$ (see Figs. 4A, B). Fault surface A showed a lower strength (up to $10.4 \mathrm{kN}$ ) and at the same time a lower degree of strength anisotropy $(5.4 \mathrm{kN})$, while the strength of fault B was generally higher (up to $12.4 \mathrm{kN}$ ) and at the same time, its degree of anisotropy was higher $(7.7 \mathrm{kN})$. On the fault $\mathrm{B}$, the expected phenomenon occurred when the strength in the direction of the fault slip was detected as the lowest strength, but on the fault A, the lowest strength was found in the opposite direction.

Due to the difficulty of obtaining natural fault surface samples, it was not possible to examine the strength pattern in oblique directions in detail, and therefore an artificial gypsum model was used, on which multiple oblique directions could be measured. Model type A with high ridges led to the square pattern with very slightly notched centers of sides in the ridge direction and very slightly raised centers of sides in a direction perpendicular to the ridges (see Fig. 5, pink line). The maximum shear strength of model type $\mathrm{A}$ is $7.95 \mathrm{kN}$ and the anisotropy is $2.72 \mathrm{kN}$. Interestingly, model type B with lower ridges has higher overall strength (up to $8.90 \mathrm{kN}$ ) and significantly greater anisotropy $(4.39 \mathrm{kN})$. At the same time, there was a gradual change in strength around the maximum and very significant notched values in the direction of the ridges (Fig. 5, red line).

\section{DISCUSSION}

The shear strength anisotropy of the real joints and faults in granite and those of the gypsum models revealed distinct trends in both cases, as shown above. The strength pattern of the real joints typically revealed one peak, while the other directions were characterized by lower strength values, which might be explained by the presence of more or less noticeable

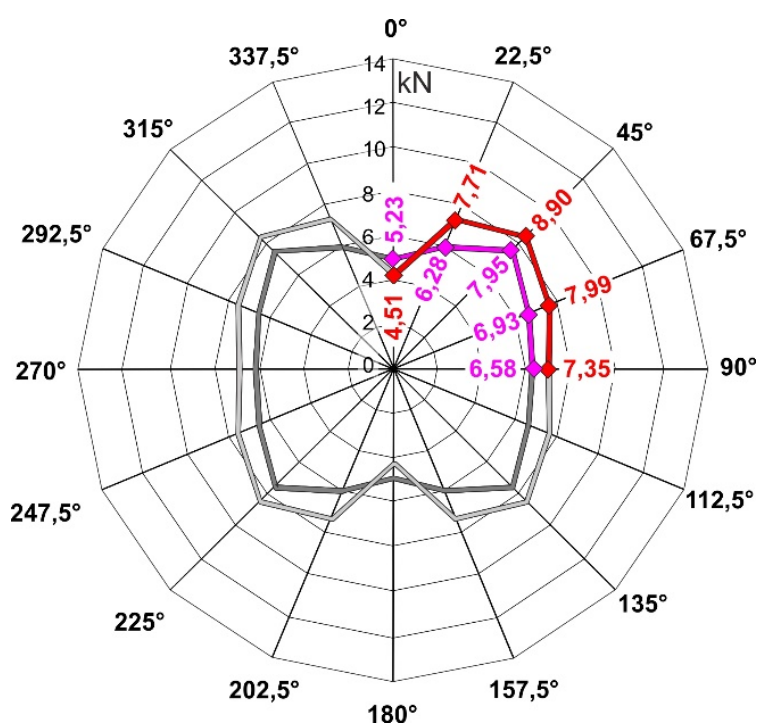

Fig. 5 Polar diagram with gypsum model testing, the average results: pink line - type A with the bigger ridges, red line - type $\mathrm{B}$ with the finer ridges.

tortuous steps on the joint surfaces. The shear strength anisotropy of the tested joints had approximately the shape of a teardrop in the polar diagram (cf. Fig. 3D). Therefore, in order to characterize the shear strength anisotropy of joints with steps, it is necessary to know the direction of maximum strength, resp. the opposite direction of minimum strength and corresponding strengths. The maximum strength then corresponds to the movement of the walls 'up the stairs', while the minimum strength of the movement 'down the stairs'.

In contrast, the real faults showed a different and more symmetrical four-cornered pattern of shear strength (Figs. 4, 5). In addition to the expected minimum along the striae, this pattern revealed 
another minimum in the direction perpendicular to the striae. Consequently, the maximums of the strength are in the oblique directions. By comparing the magnitudes of shear strength in the direction of tectonic slip and the opposite direction, it was possible to define two subtypes of this four-cornered pattern: (1) asymmetrical subtype with the lowest shear strength values in slip directions (cf. Fig. 4B), and (2) more-or-less symmetrical subtype with approximately equal strengths in slip direction and opposite direction (cf. Figs. 4A and 5). Subtype (1) is conditioned by the abundant presence of markedly asymmetric structures indicating the sense of tectonic movement. These structures are usually well preserved when the movement of the fault walls has not reached large values. In the opposite cases, with large or multiple movements, these structures are usually erased and, as a result, the more symmetrical pattern is formed as in the case of subtype 2. Minimal strength in the direction of the ridges was also observed in artificial gypsum models, which were designed so as not to complicate the asymmetry in the direction of movement along the ridges corresponding to the striae on natural fault surfaces. The gypsum models thus showed the ideal pattern of subtype 2 and made it possible to observe other properties of the four-cornered pattern.

Both subtypes of the four-cornered pattern surprisingly revealed a less significant minimum in the directions perpendicular to the striae or ridges, which was sometimes higher than the strength values in the longitudinal directions. This result indicates some unknown strength character of the striated planes. Although the testing of real samples is relatively difficult and limits the acquisition of more statistically significant data, this effect was also recognized in the gypsum models. The presence of perpendicular minima is logically related to the formation of maxima in the strength in oblique directions. Under the given test conditions (angle difference $45^{\circ}$ for natural samples and $22.5^{\circ}$ for gypsum models), maxima were found at an angle of $45^{\circ}$ for both natural samples and gypsum models.

The maximum strength at an angle of $45^{\circ}$ seems to indicate a compromise solution of the two weakening processes, which act against each other in perpendicular directions. The first of them is the easy slip in the direction of the striation, which leads to a minimum strength in the longitudinal direction with striae, resp. ridges (it is 'longitudinal minimum'). With a deviation from this direction, the shear strength increases and would logically be highest in the perpendicular direction if the second process did not act. The second weakening process is determined by the easy tearing off of the ridges in the transverse direction. In this direction, the profile of the ridges is the highest in relation to their width, and in terms of tearing, the situation is the most favorable (it is 'transverse minimum'). With a deviation from the transverse direction, the width of the ridge profile in the shear direction increases while maintaining the same height, and thus the difficulty of tearing them apart by shear deformation and shear strength increases.

\section{CONCLUSIONS}

Combining shear strength anisotropy under constant loading stress on joint and fault surfaces from natural granodiorite fractures and gypsum models revealed two patterns of specific strength behavior. The first type is related to joints with asymmetric tortuose tensile steps, but without distinct striations. It is typical of the presence of one distinct shear strength maximum in one direction and shear strength minimum in the opposite direction, so the strength distribution in the polar graph has a teardrop shape.

The second type is related to the striated fault surfaces with or without the asymmetric structures according to the slip direction (subtypes 1 or 2 ). We created the artificial gypsum models for this type (subtype 2), which allowed a more detailed characterization of this type. This type of pattern is characterized by two axial directions of minimal shear strength, i.e., longitudinal and transverse, and by two axial oblique directions with maximal shear strength, so the strength distribution in the polar graph has a four-cornered shape. We interpret this pattern as the sum of softening in the longitudinal direction (easy sliding along the ridges) and strengthening with a deviation from the transverse direction (less easy tearing off the ridges).

The determination of the strength of real samples and gypsum models showed that the shear strength of the joints and fault surfaces is anisotropic. This anisotropy reached up to $65 \%$ of maximum strength on joints, up to $62 \%$ on fault surfaces, and at least on the surfaces of gypsum models, where it was almost $50 \%$. Therefore, the anisotropy of the shear strength is a demonstrably very important feature of real fractures, and it is necessary to take it into account in technical calculations. Our study presented an original approach applicable for fracture modeling, landslide analyses and stabilization, and tunneling.

\section{ACKNOWLEDGMENTS}

The research was supported in part by the project 'Research team for radioactive waste disposal and nuclear safety' (reg. CZ.1.07/2.3.00/20.0052) and in part by the project GAČR 22-24206J.

\section{REFERENCES}

Agliardi, F., Crosta, G.B., Meloni, F., Valle, C. and Rivolta, C.: 2013, Structurally-controlled instability, damage and slope failure in a porphyry rock mass. Tectonophysics, 605, 34-47. DOI: $10.1016 /$ j.tecto.2013.05.033

Bailly, D., Matray, J. and Ababou, R.: 2014, Temporal behavior of a ventilated claystone at the Tournemire URL: Cross-spectral analyses focused on daily harmonics. Eng. Geol., 183, 137-158. DOI: $10.1016 /$ J.ENGGEO.2014.10.005 
Baroň, I., Agliardi, F., Ambrosi, C. and Crosta, G.B.: 2005, Numerical analysis of deep-seated mass movements in the Magura Nappe; Flysch Belt of the Western Carpathians (Czech Republic). Nat. Hazards Earth Syst. Sci., 5, 3, 367-374.

DOI: $10.5194 /$ nhess-5-367-2005

Barton, N. and Choubey, V.: 1977, The shear strength of rock joints in theory and practice. Rock Mech. Rock Eng., 10, 1-2, 1-54. DOI: 10.1007/BF01261801

Cloutier, C., Locat, J., Charbonneau, F. and Couture, R.: 2015, Understanding the kinematic behavior of the active Gascons rockslide from in situ and satellite monitoring data. Eng. Geol., 195, 1-15. DOI: 10.1016/j.enggeo.2015.05.017

Cottrell, B., Tatone, B.S.A. and Grasselli, G.: 2011, Joint replica shear testing and roughness degradation measurement. In: Zhao, J., Labiouse, V., Dudt, J.-P. and Mathier, J.-F. (Eds): EUROCK 2010. Rock Mechanics in Civil and Environmental Engineering, 4 pp. DOI: $10.1201 / \mathrm{b} 10550$

Doblas, M., Mahecha, V., Hoyos, M. and López-Ruiz J.: 1997, Slickenside and fault surface kinematic indicators on active normal faults of the Alpine Betic Cordilleras, Granada, southern Spain. J. Struct. Geol., 19, 2, 159-170.

Gentier, S., Riss, J., Archambault, G., Flamand, R. and Hopkins, D.: 1999, Influence of fracture geometry on shear behavior. Int. J. Rock Mech. Min. Sci., 37, 161174.

Glowacka, E., Sarychikhina, O., Súarez, F., Nava, F. and Mellors, R.: 2010, Anthropogenic subsidence in the Mexicali Valley, Baja California, Mexico, and slip on the Saltillo fault. Environ. Earth Sci., 59, 1515-1524.

Grasselli, G. and Egger, P.: 2000, 3D surface characterization for the prediction of the shear strength of rough joint. In: Proc. Eurock 2000, Aachen, Germany, 281-286.

Grasseli, G. and Egger, P.: 2002, Constitutive law for the shear strength of rock joints based on threedimensional surface parameters. Int. J. Rock Mech. Min. Sci., 40, 1, 25-40.

Instruction Manual: 2006, Instruction Manual Portable Rock Shear Box Assembly, MATEST.

Kabeya, K.K. and Legge, T.F.H.: 1997, Relationship between grain size and some surface roughness parameters of rock joints. Int. J. Rock Mech. Min. Sci., 34, 3-4. DOI: 10.1016/S1365-1609(97)00186-X

Kulatilake, P.H.S.W., Shou, G., Huang, T.H. and Morgan, R.M.: 1995, New peak shear strength criteria for anisotropic rock jonts. Int. J. Rock Mech. Min. Sci. Geomech. Abstr., 32, 7, 673-697. DOI: 10.1016/0148-9062(95)00022-9

Kulatilake, P.H.S.W., Um, J., Panda, B.B. and Nghiem, N.: 1998, Development of a new peak shear strength criterion for anisotropic rock joints. Int. J. Rock Mech. Min. Sci., 35, 4, 418-420.

Kulatilake, P.H.S.W., Um, J., Panda, B.B. and Nghiem, N.: 1999, Development of new peak shear - strength criterion for anisotropic rock joints. J. Eng. Mech., $125,9,1010-1017$.

Maerz, N.H., Franklin, J.A. and Bennett, C.P.: 1990, Joint roughness measurement using shadow profilometry. Int. J. Rock Mech. Min. Sci. Geomech. Abstr., 27, 5, 329-343. DOI: 10.1016/0148-9062(90)92708-M
MATEST: 2019, MATEST S.p.A.

Online: http://www.matest.com/en/product/a129rock-shear-box-apparatus (15. 12. 2019).

McWilliams, P.C., Kerkering, J.C. and Miller, S.M.: 1993, Estimation of shear strength using fractals as a measure of rock fracture roughness. Bureau of Mines, USA.

Navarro, V., Moya, M., Asensio, L., Yustres, T., García, B. and Sánchez, J.: 2014, A multicriteria system for the monitoring and alert of the cracks found in Santos Morcillo Lake, Central Spain. Int. J. Disaster Risk Reduct., 10, 1-14.

Nordvik, T., Blikra, L., Nyrnes, E. and Derron, M.: 2010, Statistical analysis of seasonal displacements at the Nordnes rockslide, Northern Norway, Eng. Geol., 114, 228-237. DOI: 10.1016/j.enggeo.2010.04.019

Osasan, K. and Afeni, T.: 2010, Review of surface mine slope monitoring techniques. J. Min. Sci., 46, 177186. DOI: $10.1007 / \mathrm{s} 10913-010-0023-8$

Petit, J.-P.: 1987, Criteria for the sense of movement on fault surfaces in brittle rocks. J. Struct. Geol., 9, 597-608. DOI: 10.1016/0191-8141(87)90145-3

Ragan, D.M.: 2009, Structural Geology. - An Introduction to Geometrical Techniques. 4th ed., Cambridge University Press, New York.

Salvini, R., Vanneschi, C., Riccucci, S., Francioni, M. and Gulli, D.: 2015, Application of an integrated geotechnical and topographic monitoring system in the Lorano Marble Quarry (Apuan Alps, Italy). Geomorphology, 241, 209-223. DOI: 10.1016/J.GEOMORPH.2015.04.009

Sarychikhina, O., Glowacka, E., Mellors, R. and Vidal, F.: 2011, Land subsidence in the Cerro Prieto geothermal field, Baja California, Mexico, from 1994 to 2005. J. Volcanol. Geotherm. Res., 204, 76-90. DOI: 10.1016/j.jvolgeores.2011.03.004

Sosna, K., Franěk, J., Vondrovic, L. and Záruba, J.: 2014, Stresses and strains induced by in situ thermal loading in granitic massif. In: 8th Asian Rock Mechanics Symposium, 14-16 October 2014, Sapporo, 2014.

Štelcl, J. and Weiss, J.: 1986, The Brno Massif. University of J.E. Purkyně, Brno, 255 pp., (in Czech).

Suppe, J.: 1985, Principles of structural geology. N.J. Prentice-Hall, Englewood Cliffs.

Van der Pluijm, B.A. and Marshak, S.: 2004, Earth structure - an introduction to structural geology and tectonic. 2nd ed., Norton \& Company, New York.

Wang, Ch., Wang, L. and Karakus, M.: 2019, A new spectral analysis method for determining the joint roughness coefficient of rock joints. Int. J. Rock Mech. Min. Sci., 113, 72-82. DOI: 10.1016/j.ijrmms.2018.11.009

Xia, C.C., Yue, Z.Q., Tham, L.G., Lee, C.F. and Sun, Z.Q.: 2003, Quantifying topography and closure deformation of rock joints. Int. J. Rock Mech. Min. Sci., 40, 197-220. DOI: $10.1016 / \mathrm{S} 1365-1609(02) 00134-\mathrm{X}$

Yang, Z.Y., Di, C.C. and Lo, S.C.: 2001, Two-dimensional Hurst Index of Joint Surfaces. Rock Mech. Rock Eng., 34, 4, 323-345. DOI: 10.1007/s006030170004

Yang, Z.Y., Taghichian, A. and Huang, G.D.: 2011, On the applicability of self-affinity conceptin scale of threedimensional rock joints. Int. J. Rock Mech. Min. Sci., 48, 1173-1187. DOI: 10.1016/j.ijrmms.2011.06.010 